\title{
OS SINOS DOBRAM PARA AS RELAÇÕES TRANSATLÂNTICAS NA ERA TRUMP
}

Solange Reis ${ }^{1}$

Tanto a eleição quanto a presidência de Donald Trump surpreenderam o mundo em muitos aspectos, entre eles a política externa e de segurança dos Estados Unidos para a Europa. Avesso aos acordos multilaterais e insatisfeito com a distribuição de custos na Organização do Tratado do Atlântico Norte (Otan), Trump fez das relações transatlânticas um teste de resistência para a ordem internacional liberal. 0 artigo identifica alguns pontos de atrito entre os aliados, como as dúvidas sobre o futuro da Otan e a saída norte-americana de dois importantes tratados de segurança: o Tratado de Forças Nucleares de Alcance Intermediário (Intermediate-Range Nuclear Forces - INF) e o Plano de Ação Conjunto Global (Joint Comprehensive Plan of Action - JCPOA). Além disso, observa a atuação de figuras no governo Trump, ou ligadas a este, para desestabilizar as instituições comuns europeias. 0 paradoxo das circunstâncias é que, ao tentar enfraquecer 0 poder da União Europeia (UE) e incentivar as políticas nacionais no bloco, o governo Trump põe em risco a aliança com a Europa, um dos principais pilares de sua hegemonia global no pós-1945.

Palavras-chave: Donald Trump; União Europeia; relações transatlânticas; ordem internacional liberal.

\section{THE BELLS TOLL FOR TRANSATLANTIC RELATIONS IN THE TRUMP ERA}

Donald Trump's election and presidency have both astonished the world in multiple ways, including in respect to American foreign and security policy for Europe. Averse to multilateral agreements and unhappy with the cost distribution in North Atlantic Treaty Organization (NATO), Trump made the transatlantic relations a resistance test to a long living liberal international order. This paper identifies some friction points among the allies, such as doubts about the future of NATO and the US withdrawal from two relevant security treaties: Intermediate-Range Nuclear Forces (INF) and Joint Comprehensive Plan of Action (JCPOA). It identifies the role of people inside or linked to Trump administration in shaking European institutions. The circumstantial paradox is that by trying to weaken European Union capabilities and encouraging national policies in the regional bloc, Trump administration risks the alliance that has been one of the pillars of American post-1945 global hegemony.

Keywords: Donald Trump; European Union; transatlantic relations; international liberal order.

\section{LAS CAMPANAS DOBLAN PARA LAS RELACIONES TRANSATLÁNTICAS EN LA ERA TRUMP}

Tanto la elección de Donald Trump como su presidencia sorprendieron al mundo de muchas maneras, incluyendo la política exterior y de seguridad de Estados Unidos para Europa. Contrario a los acuerdos multilaterales y descontento con la distribución de costes en la Organización del Tratado del Atlántico Norte (OTAN), Trump hizo de las relaciones transatlánticas una prueba de tensión para el orden internacional liberal. El artículo identifica algunos puntos de fricción entre los aliados, como las dudas sobre el futuro de la OTAN y la retirada de EE.UU. de dos importantes tratados

1. Pesquisadora do Instituto Nacional de Ciência e Tecnologia para Estudos sobre os Estados Unidos (INCT-INEU). E-mail: <reissolange@gmail.com>. 
de seguridad: las Fuerzas Nucleares de Alcance Intermedio (FNI) y el Plan de Acción Conjunto Global (JCPOA). Además, observa las acciones de figuras del gobierno de Trump, o vinculadas a él, para desestabilizar las instituciones comunes europeas. La paradoja de las circunstancias es que, al tratar de debilitar el poder de la Unión Europea (UE) y fomentar las políticas nacionales en el bloque, el gobierno de Trump pone en riesgo la alianza con Europa, uno de los principales pilares de su hegemonía global post-1945.

Palabras clave: Donald Trump; Unión Europea; relaciones transatlánticas; orden internacional liberal. JEL: F50.

\section{INTRODUÇÃO}

Contra as máquinas e frações partidárias, a oposição de boa parte da mídia tradicional, a incredulidade internacional e a quase totalidade das previsóes, Donald Trump elegeu-se, em 2016, o 45o presidente dos Estados Unidos.

Um forasteiro na política, com propostas de campanha de difícil transposição para a presidência: nacionalismo econômico, retraçáo internacional, fim do multilateralismo, revisão das alianças estratégicas. Temas estranhos à política externa norte-americana no pós-1945. Prevalecia, não obstante, o consenso entre os que viam sua ascensão como uma excepcionalidade, de que as dinâmicas sistêmicas domésticas e externas preservariam o internacionalismo liberal e a estabilidade da ordem hegemônica. Trump seria neutralizado pelo sistema.

Talvez pela falta de precedente nacional - Richard Nixon não chegou perto do grau de anormalidade de Trump -, as análises ficaram aquém do fenômeno. A isca usada pelo candidato Trump para conquistar o eleitor vitimado pela globalização tornou-se o combustível de medidas desordenadas de política externa, com consequências para a economia, a geopolítica e as relações internacionais.

Com açôes e palavras de líder de um hegemon ressentido, e não do "mundo livre", o presidente sinalizou que a potência não mais daria ao mundo bens comuns, livre-comércio e instituiçóes democráticas. Ora, este havia sido o mantra do liberalismo que, com o apoio de intervençóes militares e a interferência política em outros países, desenvolvera e mantivera a hegemonia dos Estados Unidos. Ao recusá-lo, Trump abandonou a grande estratégia das últimas décadas sem propor outra em troca. Iniciou, portanto, um vácuo estratégico no momento histórico de transformação sistêmica da ordem internacional.

Requentando slogans passados - Make America Great Again e America First -, Trump e seu círculo próximo propóem reformas nas áreas de declínio relativo dos Estados Unidos, principalmente no comércio internacional. Travam, pois, uma guerra comercial com a China, a potência ascendente. Igualmente, categorizam os chineses como a maior ameaça à segurança nacional e global, o que os leva a intensificar parcerias e exercícios militares na região da Ásia-Pacífico. Hoje, a disputa entre a China e os 
Estados Unidos pelo alinhamento de países no Sudeste Asiático, na Oceania e na Ásia Central aumenta a militarização e o risco de conflitos nessas regióes.

A China não é o objeto deste capítulo, mas vale a pena lembrar que algumas teorias das relações internacionais analisam o cenário como típico da disputa por poder. De acordo com muitas dessas escolas de pensamento, sobretudo as realistas, a potência dominante agarra-se à ordem vigente e às alianças para barrar o poder contestador.

Trump, porém, não segue a cartilha. Repele a China, mas também os aliados; rejeita a ordem na qual os Estados Unidos ergueram a sua hegemonia; revela-se um reformista da supremacia e, ao mesmo tempo, um revisor das bases que a sustentam.

A analogia é corriqueira, mas como não associar tal estratégia ao ato de atirar a água e o bebê para fora da banheira? Pois o domínio mundial norte-americano sustenta-se sobre a ordem liberal internacional, que, por sua vez, baseia-se em instituições multilaterais e em cooperação e interdependência entre as potências do conceito ampliado de Ocidente.

Nenhum elo nessa roda de interesses é mais relevante que as relaçóes Estados Unidos-União Europeia (UE). São elas que definiram as regras, os meios, os vencedores, os perdedores e a legitimidade do jogo mundial depois da Segunda Guerra Mundial.

As ditas relaçóes transatlânticas, porém, têm em Trump um desafio inédito. $\mathrm{Na}$ primeira metade do mandato, cresceram as críticas quanto às "práticas comerciais desleais” pela UE. Após uma quase guerra tarifária em 2018, envolvendo aço, alumínio, carros e motocicletas, os dois lados fizeram uma trégua de duração incerta.

No campo da segurança, os atritos seguem acerca das relaçóes com a Rússia e da soluçấo para a Síria e a Ucrânia, mas centram-se no custeio desequilibrado da Organização do Tratado do Atlântico Norte (Otan) e na manutenção do acordo para o programa nuclear iraniano. A divergência sobre o Irã tende a gerar efeitos relevantes na geopolítica do Oriente Médio e para o sistema financeiro internacional. Além disso, a saída norte-americana do Tratado de Forças Nucleares de Alcance Intermediário (Intermediate-Range Nuclear Forces - INF) deixa a Europa, bem como o mundo, à mercê de uma nova corrida armamentista.

O capítulo faz um recorte na política externa e de segurança norte-americana na primeira metade do mandato de Donald Trump, enfocando o tratamento dos Estados Unidos para a Europa no quesito segurança. A segunda seção traz alguns comentários sobre a ordem liberal pós-1945; a terceira trata das desavenças sobre custos e responsabilidades na Otan; a quarta aborda a criação de uma plataforma de pagamentos europeia para burlar as sançôes contra o Irấ; a quinta analisa a 
saída dos Estados Unidos do Tratado INF; e a sexta seção, por fim, apresenta as considerações finais.

\section{LEVIATÃ EM CRISE DE AUTORIDADE}

"Estados liberais são diferentes. São realmente pacíficos entre eles" (Doyle, 1986, p. 1151). Embora reconheça a indefinição do termo liberalismo, o autor considera que as nações liberais são uma espécie de retrato de família de princípios e instituições com características comuns. Assim, no campo internacional, Estados liberais possuem os mesmos objetivos, criam oportunidades recíprocas no comércio e se aliam contra suas contrapartes autoritárias. Se bem-sucedida, a aliança liberal geraria a paz democrática.

$\mathrm{Na}$ segunda metade do século XX, os Estados Unidos agiram como um leviatá liberal e construíram a mais ambiciosa e extensa ordem hegemônica (Ikenberry, 2011). Instituiçóes multilaterais e alianças especiais são características desse sistema, com fornecimento de segurança e criação de riqueza em troca de alinhamento geopolítico, jurídico e ideativo.

Os Estados Unidos não apenas incentivaram a ordem aberta e baseada em regras.

Tornaram-se o organizador hegemônico e gerente dessa ordem. O sistema político americano - e suas alianças, tecnologia, moeda e mercados - se fundiram à ordem liberal mais ampla (Ikenberry, 2011, tradução nossa).

As relaçôes transatlânticas produziram e refletiram o equilíbrio estratégico no pós-guerra. De um lado, os Estados Unidos entregando proteção militar e estabilidade para o crescimento econômico dos países europeus e a sustentabilidade do capitalismo; do outro, as naçóes europeias ajudando a criar e a dar legitimidade às normas que sustentam o sistema internacional na Pax Americana.

Engana-se quem pensa que fossem relaçóes de igualdade, pois aquelas obedeciam a uma hierarquia não imposta, ainda que à Europa não restassem muitas escolhas. Os Estados Unidos foram para os europeus um "império a convite" (Lundestad, 2003).

Tendo durado até a década de 1970, tal cortejo tornou-se mais condicional, embora nunca tenha sido totalmente retirado. $\mathrm{O}$ alargamento e o aprofundamento da comunidade europeia, bem como o colapso do sistema monetário de Bretton Woods e a posterior criação do euro, representaram pontos de bifurcação, mas não destruíram a aliança liberal.

Diversos resultados surgiram dessa cooperação, tais como o sistema de segurança coletiva (Otan), as instituiçôes financeiras (Banco Mundial e Fundo Monetário Internacional - FMI), as organizaçôes de comércio - Acordo Geral de Tarifas e Comércio (General Agreement on Tariffs and Trade - GATT) e 
Organização Mundial do Comércio (OMC). Outros menos tangíveis abrangem consensos em resoluçôes da Organização das Nações Unidas (ONU), alinhamento diplomático em questôes internacionais e pactuação na promoção de interesses dos países industrializados.

O elemento geopolítico de ligação dessa massa razoavelmente homogênea foi a existência de um inimigo comum centrado na figura da União Soviética. O fim da Guerra Fria chegou a levantar dúvidas sobre a sustentabilidade da aliança militar e ideológica. Afinal, que papel caberia à Otan sem seu alter ego? Como encaixar a Alemanha reunificada no novo contexto? O que fazer com a normalização das relaçóes russo-europeias?

O liberalismo internacional, contudo, ganhou sobrevida, gerando arroubos de otimismo acerca de sua vitória definitiva sobre qualquer ideologia (Fukuyama, 2006).

Sem a distopia de Fukuyama (2006), Ikenberry (2011) também pôs as fichas na continuidade da ordem liberal. Os Estados Unidos tinham se envolvido tão profundamente com o Ocidente ampliado e as instituiçóes multilaterais que seria impossível desvincular-se. Ainda que o desprendimento fosse possível, nenhum presidente o faria, por receio da inevitável punição.

Com a invasão infundada do Iraque, em 2003, as relaçóes transatlânticas expuseram fissuras. França e Alemanha recusaram-se a participar da guerra e criticaram abertamente o aliado. George W. Bush contra-atacou, categorizando os países europeus em velha e nova Europa, e os incitou a escolher lados.

Posteriormente, refletindo sobre aquele período, Ikenberry (2011) constatou que o unilateralismo de George W. Bush havia posto a ordem hegemônica em crise de autoridade. A solução (e o desafio) não seria criar uma nova ordem, mas ater-se à velha.

O poder é mais durável e legítimo quando exercido em um sistema de regras. (...) O desafio para os Estados Unidos nas próximas décadas é manter essa lógica de construção da ordem, mesmo quando os fundamentos mais profundos da ordem internacional liberal mudarem (Ikenberry, 2011, tradução nossa).

A presidência de Barack Obama oxigenou a confiança no multilateralismo e no internacionalismo liberal, não obstante ter sido sob o seu governo que um distanciamento prático aconteceu. Com o democrata, os Estados Unidos reduziram o número de bases militares na Europa e criaram o conceito de pivô asiático, relegando a segurança da Europa a segundo plano. Além disso, a revelação da espionagem da Agência de Segurança Nacional (National Security Agency - NSA) sobre a chanceler da Alemanha, Angela Merkel, expôs problemas de respeito e confiabilidade.

Depois da eleição de Trump, Walt (2018) constatou que o risco de quebra da ordem liberal partia dos Estados Unidos, observando que o "realismo neandertal" do republicano em relação à UE pretende "dividir para mandar". 
A ampla abordagem de Trump à Europa é "dividir para reinar". Ele chamou a UE de "inimigo" dos Estados Unidos e apoiou várias forças políticas que agora perturbam o continente e ameaçam a política de longo prazo da UE. Porque ele acha que dividir a Europa em Estados em disputa permitirá que os Estados Unidos, maiores e mais poderosos, negociem com cada Estado europeu separadamente, em vez de enfrentá-los todos juntos, e assim garantam melhores negócios para si (Walt, 2018, tradução nossa).

$\mathrm{O}$ ataque frontal à UE tem respaldo no pensamento da extrema direita que abriu frente internacional neste final da segunda década dos anos 2000. Um dos porta-vozes dessa tendência, Steve Bannon, que foi o estrategista-chefe da Casa Branca e um dos artífices da campanha eleitoral e da política externa de Trump, defende o nacionalismo econômico e responsabiliza o estrangeiro - seja ele o imigrante que concorra ou não como força de trabalho, seja uma nação desejosa de obter vantagens das regras do livre-comércio - pelo declínio dos Estados Unidos e dos trabalhadores brancos, sobretudo das áreas rurais do país.

Stokes (2018, tradução nossa) argumenta que "a vitória de Trump representa (...) a rearticulação da primazia do Estado-nação, uma fratura no consenso internacionalista liberal do pós-guerra e o endurecimento do revisionismo geopolítico".

O voto britânico para deixar a UE (possivelmente uma criação tanto dos Estados Unidos quanto de seus membros europeus) enfraqueceu uma das instituiçóes mais importantes da ampla ordem internacional liberal, liderada pelos Estados Unidos. Mais desestabilizadora para as fundaçóes da ordem liberal internacional tem sido a eleiçáo do presidente Trump. Seu governo tem incentivado, ativamente, a dissolução da UE, questionado as duradouras alianças globais de segurança dos Estados Unidos, como a Otan, e viu a defesa de um nacionalismo econômico que ameaça reverter a globalização (Stokes, 2018, tradução nossa).

Embora considere difícil avaliar a extensáo do desvio da grande estratégia e do dano à liderança dos Estados Unidos, Stokes (2018) não vê a ruptura como definitiva. No cenário pós-Trump, as elites norte-americanas retornarão ao status quo ante bellum, haja vista os benefícios obtidos com a hegemonia.

Mesmo de uma perspectiva crítica, Stokes (2018) reforça a crença no excepcionalismo americano e nas forças sistêmicas. Desconsidera nuances domésticas, como a conversão da classe trabalhadora ao credo ultraconservador e religioso que embasa as políticas do atual governo (Moraes, 2018), um movimento politicamente calculado que remonta aos tempos de Ronald Reagan. Em outras palavras, Trump não seria a causa, mas o sintoma.

A confiança do autor de que os Estados Unidos preservarão suas vantagens absolutas e relativas, tais como a força do dólar e a primazia militar, minimiza a perda do que Ikenberry (2011) sugeriu preservar: autoridade política global. 


\section{RÉQUIEM PARA 0 INTERNACIONALISMO LIBERAL}

Os ataques ao que o presidente considera oportunismo da UE, principalmente de seu núcleo centrado na Alemanha e na França, antecedem à eleição. Há pouco tempo, o apoio explícito de Trump ao Brexit e o envolvimento de seus assessores de campanha no movimento que promoveu o referendo para a saída do Reino Unido do bloco europeu seriam impensáveis. Hoje, tudo isso é tratado sem pudor diplomático.

De fato, a atual diplomacia transatlântica está mais para intrigas renascentistas que para a sociabilidade de Estados como solução para a anarquia do sistema internacional.

Há vários exemplos da inversão na ética diplomática para a Europa na era Trump, dos quais pode-se destacar a nomeação de Richard Grenell para a embaixada em Berlim. Grenell é dublê de articulista de imprensa e diplomata. Ocupou o cargo de diretor de comunicaçóes e diplomacia pública na ONU durante o governo de George W. Bush; assessorou vários políticos conservadores no Partido Republicano; fundou a Capitol Media Partners, consultoria de estratégia de comunicação, com forte circulação em Washington e na mídia.

Depois de assumir o posto em Berlim, disse a que veio. "Agora é a hora do conservadorismo político na Europa. (...) Quero, com certeza, fortalecer outros conservadores na Europa toda" (Tomlinson, 2018).

O comentário de Grenell fere o art. 41 da Convenção de Viena sobre o Direito dos Tratados, que determina a náo interferência de diplomatas nos países hospedeiros. Exatamente por isso, exemplifica um novo padrão nas relaçōes do governo Trump com os europeus.

Sua nomeação é parte de uma engrenagem ultraconservadora e conecta-se, direta ou indiretamente, à segunda prova de que a qualidade da relação transatlântica se deteriorou. Trata-se da cruzada de Bannon para fortalecer partidos de extrema direita no continente.

Bannon diz ter como objetivo "atravessar uma estaca no coração do vampiro”, referindo-se a Bruxelas como o centro do projeto globalista (Lewis, 2018). Em bom português, o plano é ajudar partidos radicais na UE a conseguir um número maior de cadeiras no Parlamento Europeu nas eleiçóes de maio de 2019, a fim de "drenar o pântano" por dentro, uma forma de autofagia do processo de integração regional. A UE é a quintessência do supranacionalismo que a direita radical representada por Bannon e afins considera a meta do globalismo, jargão midiático para os apoiadores da globalização.

Para matar o vampiro, Bannon criou o fórum The Movement (O movimento), em parceira com Mischaël Modrikamen, fundador do partido belga de extrema 
direita Parti Populaire. Sem a ilusão de conseguir uma maioria de eurocéticos no parlamento no curto prazo, ambos esperam avançar pautas sobre soberania nacional, fechamento de fronteiras, anti-islamismo, nacionalismo econômico e redução de direitos humanos. O objetivo: fragilizar as instituiçôes comuns internamente e a atuação do bloco em âmbito externo.

O Brasil não é uma instituição supranacional, mas nem por isso escapou dos tentáculos do The Movement. Afinal, as circunstâncias históricas favorecem. No início de fevereiro, um press release (comunicado de imprensa) do fórum anunciou Eduardo Bolsonaro, deputado federal e filho do presidente brasileiro de extrema direita, Jair Bolsonaro, como o líder do The Movement no país e representante na América Latina (Son..., 2019).

A história da integração regional viu embates constantes entre forças nacionais e comunitárias, não sendo incomum avanços e retrocessos para ambos os lados. O "euroceticismo" é uma corrente institucionalmente constituída nas políticas domésticas e no Parlamento Europeu, mas o momento atual é inédito quanto à interferência extrarregional aberta. Nem mesmo a Rússia, que tem a perder conforme o bloco se fortalece, costuma ser tâo pouco diplomática como o atual governo norte-americano.

Os efeitos do The Movement são notados para além de países como Hungria, Polônia, República Tcheca, Itália - este último a base física atual de Bannon. Em dezembro, o governo belga se desintegrou devido às divergências quanto ao Pacto Global de Migração da ONU, compromisso do qual o governo norte-americano (seguido por Bolsonaro) se retirou por alegada incompatibilidade com a soberania nacional. A Suécia, por sua vez, mergulhou em uma crise política depois da vitória dos nacionalistas de raízes nazistas nas eleições de setembro. O último país a sofrer o efeito dominó do populismo de ultradireita é a Espanha.

Bannon não está sozinho na guerra contra o que chama de burocratas de Bruxelas. Um reforço importante vem do secretário de Estado dos Estados Unidos, Mike Pompeo. Em dezembro de 2018, na capital europeia, Pompeo enalteceu o papel do país como salvador da paz global, mas lembrou que a missão é afirmar a soberania nacional antes da ordem internacional. "A questão central que enfrentamos é saber se o sistema atualmente configurado (...) funciona" (Herszenhorn, 2018).

\section{ELOS PERDIDOS DA SEGURANÇA COLETIVA}

Com as relaçóes transatlânticas atingindo seu ponto mais baixo, o foco volta-se para uma instituição comum: a Otan. Uma mostra sarcástica deste novo cenário aconteceu quando Trump entregou uma fatura para Angela Merkel durante a visita da primeira-ministra alemã à Casa Branca, dois meses após a posse do 
republicano. Tratava-se de uma cobrança simbólica de mais de US\$ 300 bilhóes relativos à suposta dívida recente da Alemanha com a Otan.

Entre as instituiçóes multilaterais do pós-guerra, poucas foram mais imunes aos solavancos da política internacional que a Otan, criada em 1949 para ser um organismo de segurança coletiva dos Estados Unidos e dos principais países europeus.

O papel norte-americano na aliança é tão dominante que o art. 13 do tratado determina que um país-membro deve comunicar aos Estados Unidos, previamente, a eventual intençáo de sair da Otan. De forma geral, o documento trata os Estados Unidos como uma espécie de sócio majoritário.

Trump não foi o único presidente a enfocar o desequilíbrio na distribuição de custos e responsabilidades entre os integrantes da organização. Em entrevista de 2016, Barack Obama criticou os países europeus que "pegam carona" na aliança transatlântica (Goldberg, 2016). Os americanos querem que os europeus cumpram o recomendado: gastar $2 \%$ do produto interno bruto (PIB) com defesa. A meta náo é factível para alguns países nem faz sentido do ponto de vista da grande estratégia individual, mas os Estados Unidos sentem-se sobrecarregados.

De fato, em 2017, os Estados Unidos gastaram 3,5\% sobre o PIB com defesa, contra 2,1\% pelo Reino Unido, 1,8\% pela França e 1,2\% pela Alemanha. $\mathrm{Se}$, hipoteticamente, os gastos nacionais com defesa de todos os membros da Otan fossem destinados apenas à organização, os Estados Unidos teriam uma participação de 71,7\%, contra 5,8\% do Reino Unido (Taylor-Wynn, 2018). Sem entrar no mérito dos benefícios estratégicos para cada integrante da Otan, considerando-se que o PIB norte-americano é mais de dez vezes superior ao britânico, a diferença é abissal na contribuição comparada entre os dois lados do oceano.

Em contrapartida, há de se ressaltar que a presença militar dos Estados Unidos no mundo é única, pois a grande estratégia não é a proteção da soberania e do território apenas, mas a supremacia política, econômica e militar. Ao mesmo tempo, países europeus têm como preocupaçáo a segurança nacional, normal para qualquer naçáo, e regional, dado o passado de guerras e o contexto contemporâneo da integraçáo.

Sob o governo Trump, a aliança viu-se na berlinda como nunca antes em seus setenta anos de existência. Já na campanha eleitoral, Trump alternava entre chamá-la de obsoleta, ressaltar sua relevância e cobrar mais contribuição dos aliados.

Em seu discurso na reuniáo anual na Otan, em 2017, Trump voltou a criticar o baixo comprometimento operacional e financeiro dos aliados e, ao não fazer referência ao art. 5 do tratado, que é a essência do compromisso da segurança coletiva, rompeu uma norma náo escrita. 
O alvo principal de irritação tem sido a Alemanha - país que simboliza o "oportunismo" criticado por Trump - e Merkel. Durante a longa gestão da chanceler, a Alemanha atingiu os menores níveis de gastos com defesa.

$\mathrm{Na}$ Conferência da Otan, em 2018, Trump perguntou para que serve a organização se a Alemanha é refém da Rússia devido à dependência energética, ressaltando sua contrariedade com a construção do gasoduto Nord Stream 2. Em uma participação carregada de semiótica, interrompeu a fala de Merkel, antes de retirar-se prematuramente da reuniáo. Espetáculo à parte, o recado fora dado náo a um aliado, mas a uma Alemanha subalterna.

Posteriormente, Trump disse que os Estados Unidos deviam inspirar-se na Suécia, que colabora com a Otan sem filiação, e enviou cartas a vários países europeus, alegando perda da paciência com o pequeno comprometimento financeiro dos aliados.

Um artigo do The New York Times, de janeiro de 2019, mostra que vários funcionários da Casa Branca revelaram que o presidente sempre manifestou vontade de abandonar a organização (Barnes e Cooper, 2019). No Twitter, Trump contradisse a notícia, afirmando que os Estados Unidos estão 100\% com a Otan.

Resta o dito pelo não dito. Nada mais indicativo da fratura transatlântica que o discurso de renúncia de Jim Mattis, secretário de Defesa, em dezembro de 2018. Um recado direto a Trump sobre o tratamento para com os aliados, não apenas os europeus, mas também Japão, Canadá e Coreia do Sul.

Devemos fazer todo o possível para promover uma ordem internacional mais propícia à nossa segurança, prosperidade e aos nossos valores, e nos fortalecermos nesse esforço pela solidariedade de nossas alianças. Porque você tem o direito de ter um secretário de Defesa cujos pontos de vista estejam mais bem alinhados com os seus sobre estes e outros assuntos, acredito ser correto que eu deixe meu cargo (Jim..., 2018, tradução nossa).

A fissura sobre a questão se estende às elites militares e políticas dentro do país, embora o afastamento seja mais retórico do que efetivo, pois os Estados Unidos não saíram da Otan e não diminuíram sua contribuição financeira. Nada do que Trump ameaçou fazer foi, de fato, realizado. A política internacional, no entanto, opera sob uma cortina de fumaça.

Como Trump abandonou o Acordo de Paris, o Acordo de Parceria Transpacífico (Trans-Pacific Partnership - TPP) e o Tratado INF, o Congresso tratou de se antecipar em relação à Otan. Em janeiro de 2019, congressistas em Washington aprovaram uma lei bipartidária que veta recursos para a saída dos Estados Unidos da aliança. Nesse sentido, a previsão de Stokes (2018) - de que as estruturas dominantes reconstruiriam os laços - ganha fôlego. 
De outro modo, da perspectiva liberal das relações internacionais, os elos de cooperação são baseados em um grau mínimo de confiança e previsibilidade. Uma vez desrespeitadas essas condiçóes, reduzem-se as chances de continuidade do sistema internacional baseado em regimes, instituiçóes e normas.

Findo o encontro da Otan, em 2017, Merkel foi clara. "Em certa medida, a era em que podíamos confiar totalmente nos outros acabou. (...) Nós, europeus, temos que pegar o nosso destino com as próprias mãos" (Paravicini, 2017, tradução nossa).

A chanceler foi ainda mais direta na Conferência de Segurança de Munique de 2019. Criticou o isolacionismo do governo Trump, ironizou a saída dos Estados Unidos do acordo com o Irã como a pior estratégia para conter Teerã e lembrou que os carros alemães não podem ser uma ameaça à segurança nacional dos Estados Unidos, se a maior fábrica da BMW fica na Carolina do Sul.

$O$ Grande Enigma: quem vai recolher os pedaços?2 é o título do relatório final da conferência, um documento pleno de afirmaçôes escatológicas sobre o fim da ordem internacional liberal e das relaçóes transatlânticas.

Apropriar-se do próprio destino em meio às amarras estruturais revela-se uma tarefa mais difícil na prática que no discurso, mas algumas iniciativas das lideranças europeias indicam a premência de ação, talvez náo em relaçáo à conjuntura temporária de Trump, mas às transformaçôes sistêmicas.

É fato que as ameaças do presidente surtiram algum efeito na distribuição de custos, pois os membros da Otan concordaram em aumentar em US\$ 100 bilhóes os gastos com defesa nos próximos dois anos (Allen, 2019).

A prova mais indicativa de que os europeus perderam a confiança na lealdade e na autoridade do aliado-mor, contudo, foi a Iniciativa Europeia de Intervenção (European Intervention Initiative - E2I), lançada pela França em 2017 como reação ao Brexit e à nova postura dos Estados Unidos. Com dez países já tendo aderido, o projeto visa desenvolver uma cultura estratégica comum e de cooperação entre as Forças Armadas.

Dada a defasagem de capacidade militar em relação a Estados Unidos, China, Rússia e outros atores do sistema internacional, a E2I tem impacto ainda simbólico. A Europa precisa de um plano C, enquanto "come pelas beiradas" com o plano A (Otan) e disfarça com o plano B (E2I).

2. Em inglês, The Great Puzzle: who will pick up the pieces?. Disponivel em: <https://bit.ly/2SuC9Nf>. 


\section{IRÃ: ELEFANTE NA SALA}

$\mathrm{Na}$ área militar, a independência continua sendo um pensamento desejoso, mas o campo político-financeiro abre algumas frentes de contestação, ainda que tímidas. O dilema em relaçáo ao Irã representa um claro sinal de busca por maior autonomia europeia, pois a questáo tornou-se o fio desencapado das relaçóes transatlânticas depois que os Estados Unidos decidiram abandonar o Plano de Ação Conjunto Global (Joint Comprehensive Plan of Action - JCPOA).

Assinado em 2015, pelo Irã e pelo grupo denominado P5+1, que inclui os cinco membros do Conselho de Segurança da ONU (China, França, Rússia, Reino Unido e Estados Unidos) e a Alemanha, o acordo definiu os termos para a continuidade do programa nuclear iraniano e a suspensão da maioria das sançóes secundárias contra Teerã. Esta categoria de sanção atinge empresas e bancos não norte-americanos engajados em determinadas transaçôes comerciais e/ou financeiras com o Irã. As sançóes primárias, que nunca foram retiradas, abrangem empresas dos Estados Unidos e estrangeiras que sejam subsidiárias de companhias norte-americanas.

Por limite de espaço, aqui não serão dados os detalhes do JCPOA. Basta resumir que, em troca de desmontar um reator, limitar a produção de urânio enriquecido e o número de centrífugas e permitir a vistoria regular de suas instalaçóes nucleares pela Agência Internacional de Energia (AIE), o Irã teve suspensa a maioria das sançóes econômicas, comerciais e financeiras impostas por Estados Unidos e UE e obedecidas por outros países ao longo de anos/décadas.

O JCPOA resultou na reinserção gradativa do Irã na economia global e em mais fluxo de petróleo, o que contribuiu para manter os preços baixos do barril nos últimos anos de débil crescimento econômico global. Para os Estados Unidos, representou um gol diplomático e o aumento da margem de ação no Iraque, onde o Irã exerce grande influência. A ação travada pelas Forças Armadas norte-americanas e iraquianas contra o Estado Islâmico no Iraque não seriam possíveis sem a concertação com o Irã e com os grupos políticos iraquianos majoritários e aliados a Teerã.

Com o acordo, países da UE recuperaram acesso ao petróleo iraniano e, principalmente, oportunidades comerciais. Antes da imposição das sançôes nos anos 2000, a UE era o principal parceiro comercial do Irã. A reabertura do mercado iraniano, ansioso por cobrir a defasagem tecnológica causada pelo longo bloqueio comercial e financeiro - as primeiras sançôes extrarregionais foram aplicadas no governo Bill Clinton -, teve forte apelo entre as empresas europeias em uma época de competiçáo industrial com os países ocidentais e as economias asiáticas emergentes.

Para citar alguns exemplos, o JCPOA permitiu que a francesa Total acertasse o desenvolvimento do South Pars, gigantesco campo de gás iraniano; a Airbus 
negociou a venda de mais de cem aviōes; as automotivas francesas ainda miram o mercado de 80 milhóes de pessoas; empresas alemãs seguem exportando máquinas, equipamentos, veículos, produtos químicos, farmacêuticos e médicos. Somente entre 2015 e 2016, as exportaçóes da Alemanha para o Irã cresceram em 27\% (German..., 2018).

Todo esse fluxo de comércio só foi possível porque as empresas europeias viram-se livres das penalidades vigentes antes da assinatura do JCPOA, e os mecanismos globais de transaçôes financeiras, liderados por Wall Street, voltaram a permitir pagamentos e recebimentos relativos ao Irá. O principal destes instrumentos é o Society for Worldwide Interbank Financial Telecommunication (SWIFT), uma plataforma de mensagens eletrônicas entre bancos no mundo todo, inclusive bancos centrais. Em termos financeiros, ficar fora do SWIFT equivale a estar em outro planeta.

Com a ameaça atual dos Estados Unidos, de reaplicar as sanções, as empresas europeias voltam a perder não só o mercado iraniano como todos os investimentos feitos no Irã nos últimos três anos.

Ainda na campanha republicana, Trump disse que o JCPOA era o "pior acordo já feito". Conforme seu governo avançou, cresceu a certeza de que o compromisso agonizava. $\mathrm{O}$ presidente pressionava pela revisão de termos e prazos (tornar sua vigência indefinida, em vez dos quinze anos estabelecidos em 2015), por vistoria às instalaçôes militares iranianas e pela inclusão de limites à produção de mísseis de longo alcance.

Para embasar as demandas, difundiu a ideia de que o Irã vinha descumprindo o acordo em vários pontos, acusaçôes refutadas pelo governo iraniano, mas também por AIE, ONU, China, Rússia, signatários europeus e pelas próprias agências de inteligência norte-americanas. Apenas a Casa Branca e parte do Congresso, junto a Israel e alguns Estados árabes, insistem na tese de que o acordo deve ser reformulado ou cancelado para tornar o mundo mais seguro.

Em maio de 2018, os Estados Unidos renunciaram ao JCPOA, reinstalando as sanções em agosto seguinte. O Irã está proibido de comprar dólar, comercializar ouro e outros metais, importar peças automotivas, avióes de passageiros e peças para aeronaves. Outras sançôes atingiram o setor petrolífero e petroquímico do país, embora uma isenção de seis meses tenha sido dada a certos compradores de petróleo iraniano, como China, Coreia do Sul, Japão, Índia e alguns países europeus.

A China e a Rússia condenam a decisão, mas são os europeus que têm feito da preservação do acordo a pièce de résistance, alegando que a sua supressão aumentará a insegurança no mundo e no Oriente Médio. Afinal, que motivações o Irã terá 
para fazer a sua parte em um compromisso abandonado pelo signatário mais relevante, por aquele que tem a capacidade de tornar o acordo inútil na prática? Caso o Irã também se retire do JCPOA, as instituiçóes internacionais perderão a capacidade de supervisionar o país quanto a armas nucleares. Este é o argumento principal da UE para resistir à determinação norte-americana, sintetizado nas palavras do presidente da Comissão Europeia, Jean-Claude Juncker.

Em Sófia, assistimos a uma demonstração da unidade europeia. Enquanto os iranianos respeitarem os seus compromissos, a União Europeia respeitará, naturalmente, o acordo de que foi arquiteta, um acordo que foi ratificado por unanimidade pelo Conselho de Segurança das Naçôes Unidas e que é essencial para preservar a paz na regiāo e no mundo. Mas as sançôes americanas não ficarão sem efeito. Temos, portanto, o dever, a Comissáo e a Uniáo Europeia, de fazer o que pudermos para proteger as empresas europeias (...) (Comissão Europeia, 2018).

Nota-se que as razôes comerciais pesam na decisão dos europeus para manter as boas relaçóes com Teerã. A empresa Airbus, por exemplo, perderá contratos da ordem de US\$ 39 bilhôes. A fim de preservar o comércio com o Irã, a UE chegou a invocar o Estatuto de Bloqueio, lei que

proíbe as empresas da UE de cumprir os efeitos extraterritoriais das sançôes dos EUA, permite às empresas a obtenção de indenizaçôes decorrentes de tais sançóes junto à pessoa causadora dos prejuízos, e anula o efeito na UE de quaisquer decisóes judiciais estrangeiras que se baseiem nelas (Comissão Europeia, 2018).

A legislação foi criada em 1996 para proteger empresas europeias que fossem alvo das sançôes implementadas pelos Estados Unidos contra Cuba, Irã e Líbia. O Estatuto de Bloqueio, no entanto, não dá às companhias europeias segurança jurídica suficiente para enfrentar as sançóes em um mundo altamente integrado, incluindo o fechamento do acesso ao mercado norte-americano e a inclusão em listas de exclusão de transaçóes financeiras nos canais globais.

Para amenizar o risco, os três países mais fortes do bloco decidiram por uma via alternativa que, se não chega a ser uma "bala de prata", tem impacto em termos políticos e monetários, sem mencionar o precedente aberto.

Em fins de janeiro, Alemanha, França e Reino Unido lançaram a plataforma de pagamentos Instrument in Support of Trade Exchanges (INSTEX). Trata-se de um veículo de propósito especial (special purpose vehicle-SPV), cuja administração será sediada em Paris, dirigido por um financista alemão e com um britânico como presidente do conselho.

A China e a Rússia concordaram em participar do sistema, depois de já terem desenvolvido seus próprios canais bilaterais de pagamento para evitar os mecanismos internacionais tradicionais manipulados pelos Estados Unidos. 
O INSTEX oferecerá um serviço de compensação, controlando uma espécie de livro-razão dos pagamentos relacionados a exportaçóes e importaçóes entre a Europa e o Irã. Em outras palavras, o SPV pretende coordenar os pagamentos, a fim de que um exportador europeu de mercadorias para o Irá possa ser pago por um importador europeu de produtos do Irâ, eliminando-se, assim, a necessidade de transaçôes cambiais.

Em princípio, abrange o comércio de alimentos, equipamentos médicos e remédios, mas o escopo poderá ser ampliado. Para o bem da verdade, a ampliação no horizonte de médio prazo é condição importante para que o Irã faça a sua parte na outra ponta e não veja o mecanismo como um instrumento de pressão indireto para a reformulaçáo do JCPOA.

O objetivo do SPV é proteger a economia iraniana, os interesses comerciais europeus e o acordo sobre o programa nuclear, desacreditando as sançóes de Trump. Além disso, o fato de Reino Unido, França e Alemanha terem tomado a iniciativa poderá encorajar outros europeus a acompanhá-los.

Embora a plataforma de pagamentos não seja completamente blindada, é provável que torne mais difícil a aplicação de sançôes contra empresas europeias, sobretudo quando estas contam com o apoio de seus países soberanos.

Mesmo que produza menos efeito que o esperado, o INSTEX já representa um afastamento político dos aliados transatlânticos. Há, por parte da EU, uma clara demonstração de inconformidade com a autoridade dos Estados Unidos. Outro réquiem para a ordem internacional liberal.

Em janeiro de 2019, um evento organizado pelos Estados Unidos, na Polônia, foi considerado um fiasco diplomático (Ward, 2019). Alemanha, França e a representante da UE não compareceram, ao passo que outros países chegaram a enviar diplomatas de segundo escalâo. Denominado Reuniâo Ministerial para Promover um Futuro de Paz e Segurança no Oriente Médio, o encontro aumentou a rachadura entre os Estados Unidos e países europeus sobre a anulação do acordo e o descontentamento mútuo.

No evento, o vice-presidente, Mike Pence, disse que o INSTEX "é um passo imprudente que só fortalecerá o Irã, enfraquecerá a UE e criará ainda mais distância entre a Europa e os Estados Unidos" (Pence..., 2019, tradução nossa). Há dúvidas quanto aos dois primeiros pontos levantados por Pence, mas o vice-presidente acerta quanto ao terceiro.

Pence não mencionou outro risco, que é o início de uma trajetória de enfraquecimento do dólar. Hoje, dois terços das transaçôes financeiras globais são feitos por meio do dólar, porém, devido às sançôes usadas de maneira indiscriminada, aliados e rivais buscam formas de evitar o sistema financeiro 
baseado na moeda norte-americana. O INSTEX é somente um entre outros instrumentos alternativos de pagamentos. Outros países, como China e Rússia, começaram a fazer comércio bilateral com pagamento em suas próprias moedas. São iniciativas pequenas, que não abalam o dólar em termos quantitativos no curto prazo, mas poderão, no médio prazo, afetar a credibilidade da moeda, uma vez que esta é usada como instrumento de securitização.

As chamadas "sançôes inteligentes" ou "sanções direcionadas" não foram inventadas por Trump, mas a escalada do seu uso como política dura traz perigos ao dólar, conforme alerta a revista liberal The Economist.

Qual é a maior fonte de poder da América? Seu poder militar é incomparável. Seu mercado é vasto. Juntamente com esses ativos está o dólar. O mundo depende da moeda dos EUA e, portanto, do acesso a sistemas de pagamentos em dólares e dos bancos nos quais a América exerce controle efetivo. (...) A maioria dos presidentes usou a arma do dólar com parcimônia. Nas últimas semanas, o governo Trump impôs duras sançóes financeiras contra a Rússia. Tendo se retirado do acordo nuclear, os EUA estão agindo contra o Irã e as empresas europeias que negociam com ele. (...) Em algum momento, isto pode acelerar o fim do dólar dominante. (...) O dólar reina supremo em parte porque os estrangeiros confiam nas instituiçôes americanas e porque seus amigos pensam que seus interesses coincidem com os da América. Se as alianças se tornarem principalmente transacionais, os esforços de outros para se livrar do dólar se intensificarão - e inevitavelmente se transformaráo em relaçôes militares e de inteligência (America..., 2018, tradução nossa).

Sachs (2018, tradução nossa) explica:

o dólar supera em muito o peso da América na economia mundial. Atualmente, os Estados Unidos são responsáveis por cerca de $22 \%$ da produçáo mundial, medida a preços de mercado, e cerca de $15 \%$ em termos de paridade de poder de compra. No entanto, o dólar responde por metade ou mais de faturas, reservas, pagamentos, liquidez e financiamento transnacionais. O euro é o principal concorrente do dólar, com o renminbi chegando em um distante terceiro lugar. (...) Os benefícios que os Estados Unidos possuem por ter a principal moeda internacional do mundo estáo diminuindo com a subida do euro e do renminbi. E, agora, as equivocadas guerras comerciais e as sanções contra o Irã, feitas pelo presidente Donald Trump, acelerarão o afastamento do dólar.

Para Sachs (2018), as vantagens para os Estados Unidos são três: $i$ ) capacidade de contrair empréstimos em dólares no exterior; ii) receitas significativas com a venda de serviços bancários para o resto do mundo; e iii) controle regulatório e supervisão dos sistemas de pagamentos.

Em suma, o uso indiscriminado das sanções "inteligentes" e do dólar como arma de política externa teria o efeito colateral de desestabilizar o sistema financeiro global ao tirar da moeda seu valor intangível de credibilidade. A consequência 
para os Estados Unidos seria a perda de um dos pilares de sua hegemonia, o único que parece ainda náo encontrar substituto no curto prazo.

\subsection{A agonia do Tratado INF}

A segurança europeia e internacional se tornou mais débil com a decisão dos Estados Unidos, em fevereiro, de abandonar o INF. Depois de acusar sistematicamente a Rússia de violar o referido tratado, devido à suposta construção um sistema de mísseis proibido, o governo Trump deu um ultimato a Moscou em outubro de 2018. O Kremlin teria que voltar a cumprir com suas obrigações, sob o risco de Washington se retirar do compromisso.

Em 2 de fevereiro de 2018, o secretário de Estado, Mike Pompeo, anunciou a saída, comunicando que o processo completo de renúncia levaria seis meses, tempo para os trâmites burocráticos determinados no INF, para a Rússia rever sua postura e para os Estados Unidos desenvolverem novas opçôes de resposta nuclear.

A Rússia, que nega as acusaçóes e culpa os Estados Unidos por descumprirem o INF, não se fez de rogada. "Responderemos quid pro quo", disse o presidente, Vladimir Putin. Horas depois de Pompeo, Putin anunciou a retirada do tratado. Assim, o processo de controle de armas entre as duas maiores potências nucleares toma o caminho perigoso da desconstruçáo, revertendo um longo processo de controle mútuo.

Os Estados Unidos e a Rússia começaram as negociações para o controle de armas na década de 1960. De lá para cá, foram ratificados grandes acordos, entre eles: Strategic Arms Limitation Talks (SALT I), INF, Anti-Ballistic Missile Treaty (ABMT) (abandonado pelos Estados Unidos em 2001), Strategic Arms Reduction Treaty (START) (venceu em 2009) e New START (vencimento em 2021). Mesmo o Tratado de Não Proliferação Nuclear (TNP) de 1968, que abrange tantas outras naçóes nucleares e não nucleares, náo teria avançado sem a vontade dos dois rivais. Com o término do INF, a renegociação do TNP em 2020 será mais complexa.

Em 1987, o INF estabeleceu que Moscou e Washington eliminariam mísseis de cruzeiro e de médio alcance lançados a partir de base terrestre, variando entre $500 \mathrm{~km}$ e $5.500 \mathrm{~km}$. Em 1991, haviam destruído 2.700 mísseis, embora continuassem livres para produzir mísseis lançados de bases aéreas e marítimas. O acordo tinha duração indefinida, mas podia ser renunciado por uma das partes, desde que respeitada a carência de seis meses e por motivos "extraordinários relacionados ao objeto do tratado", sem que a decisão precisasse de autorização legislativa.

Tal documento representou um marco histórico para o equilíbrio de forças, pondo freios na corrida armamentista. Foi um importante instrumento no 
desfazimento da bipolaridade no sistema internacional, pois é difícil imaginar o fim da Guerra Fria e o avanço da Otan para o Leste Europeu sem aquele acordo.

De fato, eram outros tempos. Ronald Reagan conseguiu que o tratado fosse ratificado por um Senado controlado pelos democratas. A União Soviética, em estágio terminal, entrava em uma transformação estrutural que levaria ao seu desmembramento e à quase partilha de seu poderio nuclear entre a Rússia e as outras antigas repúblicas soviéticas.

Havia nos Estados Unidos duas correntes sobre o espólio soviético. A primeira preferia concentrar as armas nucleares na Rússia, país com o qual Washington já havia desenvolvido canais políticos e militares. $\mathrm{O}$ arsenal atômico estaria mais seguro sob o Kremlin do que espalhado pelas outras repúblicas independentes, cuja situação política era ainda mais incerta que a da Rússia. A maioria das armas fora do solo russo ficava na Ucrânia, o que faria dessa nação independente a terceira maior potência nuclear do mundo.

Outra linha de pensamento acreditava ser um erro estratégico concentrar as armas na Rússia e preservar a paridade nuclear. Este grupo acabou derrotado. Moscou fez acordos bilaterais para a remoção das armas da Belarus e do Cazaquistão, enquanto os Estados Unidos seguiram as tratativas com o Kremlin e a Ucrânia para a concentração dos mísseis "ucranianos" em território russo.

O resultado dessa negociação foi a Declaração Trilateral de 1994 (Trilateral Statement of 1994) entre Estados Unidos, Rússia e Ucrânia. Quando da incorporaçáo da Crimeia pela Rússia, em 2015, os ucranianos lembraram aos Estados Unidos uma condição da Declaração Trilateral, que garantia à Ucrânia proteção por parte dos signatários.

No governo Obama, os Estados Unidos acusaram a Rússia de violar o tratado com o desenvolvimento do míssil de cruzeiro SSC-8, nome dado pela Otan, ou 9M729, como chamado pelos russos. Outra denúncia é que Moscou vinha fazendo testes com um tipo de míssil balístico intercontinental (intercontinental ballistic missile - ICBM) em distâncias em torno de 2 mil metros.

A Rússia rejeita a acusação e diz que os Estados Unidos romperam o INF em três pontos: i) usando mísseis banidos para testes; ii) implantando drones que são efetivamente mísseis de cruzeiro; e iii) instalando em solo terrestre da Romênia um lançador para míssil de cruzeiro, o Aegis Ashore - ou MK-41. A Polônia seria o próximo país planejado para sediar um lançador semelhante.

Quinze dias antes da denúncia do INF pelo governo Trump, representantes das duas potências se encontraram para tentar um entendimento de último minuto. A proposta russa foi provar que o 9M729 não está na categoria dos mísseis proibidos pelo tratado, desde que os Estados Unidos fizessem o mesmo 
em relação ao lançador MK-41. Os americanos rejeitaram a oferta. Uma semana depois, os russos fizeram uma demonstração para adidos militares, com a imprensa explicando que o míssil precisaria carregar uma ogiva maior e ter outra espécie de sistema de direção para ser do tipo banido. Nenhum representante da Otan ou do Pentágono compareceu, alegando tratar-se de um evento de relaçóes públicas e que o teste estático não garantia a conformidade (Woolf, 2019).

O fato é que, justificavelmente ou não, os Estados Unidos têm outros motivos para abandonar o INF. Uma das alegaçóes do governo é eliminar as barreiras que os impediriam de enfrentar a China em igualdade de condiçôes na Ásia-Pacífico, posicionando lançadores em território japonês, filipino e norte-australiano.

De acordo com o documento Nuclear Posture Review (United States of America, 2018, p. 6, tradução nossa), emitido pelo Pentágono em 2018, "desde 2010, vimos o retorno da competição entre grandes potências. Em graus variados, a Rússia e a China deixaram claro que buscam revisar substancialmente a ordem internacional e normas de comportamento do pós-Guerra Fria”.

Os Estados Unidos, que veem hoje o país asiático como ameaça superior à Rússia, se sentem em desvantagem para enfrentar o poderio nuclear chinês. A intenção por trás do abandono do tratado seria abrir negociaçóes para transformá-lo em um compromisso tripartite entre Washington, Moscou e Pequim, ou dar início a negociaçóes para um acordo novo.

Considerando o estado de limbo do INF, é difícil fazer prognósticos. Já é possível, porém, apontar os primeiros perdedores: Otan e Europa.

Como organização, a reação da aliança foi solidária com os Estados Unidos.

Os aliados concluíram que a Rússia desenvolveu e implantou um sistema de mísseis, o 9M729, que viola o Tratado INF e representa riscos significativos para a segurança euro-atlântica. Apoiamos firmemente a constatação dos Estados Unidos de que a Rússia está em violação material de suas obrigaçôes sob o Tratado INF. (...) Os Estados Unidos mantiveram o pleno cumprimento de suas obrigaçôes nos termos do Tratado INF, desde sua entrada em vigor. Os aliados enfatizam ser insustentável uma situaçáo em que os Estados Unidos e outros países respeitem totalmente o tratado, e que a Rússia não (Statement..., 2018, tradução nossa).

Entre a opiniâo coletiva da Otan e a de seus integrantes, existe diferença. Alguns países europeus embasam as alegaçóes dos Estados Unidos sobre as violaçôes da Rússia; outros não estấo convencidos. Essa divisão reflete a relação de cada um deles com a própria Rússia e a qualidade do relacionamento com Washington nos últimos anos. As respostas europeias variaram. A França e a Alemanha, por exemplo, consideram a saída um erro. O Reino Unido e países no Leste Europeu, por seu turno, apoiam a decisão dos Estados Unidos. 
Em termos da segurança em si, pouca coisa muda, pois a Europa já está ao alcance dos mísseis convencionais russos ou de uma eventual América hostil. A questão relevante é política, uma vez a decisão de renunciar ao tratado mostra que os Estados Unidos desconsideram os interesses dos aliados europeus ou da Otan. Assim, a Europa vai saindo do radar estratégico do país norte-americano, para ganhar autonomia, por um lado, e um tanto de insegurança e incerteza, por outro.

Os próximos anos de governo Trump, sejam eles o suficiente para fechar o primeiro mandato ou o tempo de uma eventual reeleição, dirão se o padrão de qualidade das relaçóes transatlânticas seguirá deteriorado ou se reverterá ao compartilhamento de interesses comuns.

Caso o primeiro cenário de afastamento na aliança se confirme, a ordem internacional liberal poderá se diluir em meio ao surgimento de polos de poder na Ásia e de uma grande estratégia norte-americana que mantenha o objetivo da supremacia, mas escolha a via do unilateralismo.

Para a Europa, haverá riscos, sobretudo quanto à segurança internacional. Isso porque o bloco está bastante longe de alcançar a autonomia militar. Em contrapartida, poderá significar mais margem de ação em termos comerciais e monetários, além de um rearranjo geopolítico para a aproximação com China e Rússia, salvaguardadas algumas reticências.

Quanto aos Estados Unidos, a dúvida não é sobre a sua capacidade de agir isoladamente, mas de sustentar o projeto hegemônico alijado de um de seus principais pilares: a parceria com os países europeus para a elaboração e a aplicação de normas dominantes em esferas multilaterais que, em maior ou menor medida, atingem os demais Estados.

Se os Estados liberais são, como descreveu Doyle (1986), um retrato de família, o divórcio parece cada vez mais próximo. Este capítulo não termina com definições ou prognósticos, mas com perguntas sobre o que reserva a história pós-Trump para a ordem mundial liberal e as relaçóes transatlânticas. Poderão e desejarão a Europa e os Estados Unidos retomar a aliança de outrora no contexto contemporâneo de rearranjo dos poderes globais e de crise do capitalismo produtivo? Ou Trump terá sido o último sino a dobrar pelo sustentáculo da ordem liberal nascida no século passado? Neste caso, que ordenamento internacional se desenhará e qual será o papel da UE nele?

\section{CONCLUSÃO}

A ascensão de Donald Trump ao posto máximo dos Estados Unidos introduziu novos elementos na política externa e de segurança do país. O multilateralismo, as alianças por afinidade e o internacionalismo liberal do passado deram lugar a 
demonstrações de isolacionismo e competição por poder. Dessa nova abordagem não escapam os aliados europeus, cuja relação com os Estados Unidos nunca esteve pior. Sáo exemplos do novo contexto a saída unilateral dos Estados Unidos do acordo com o Irã - o qual a Europa vem mostrando-se disposta a defender a qualquer custo -, a decisão de Washington de deixar o tratado nuclear INF, a alocação de diplomatas e influenciadores políticos norte-americanos em solo europeu, para catapultar partidos eurocéticos, e a intensificação da divergência sobre a divisão de gastos da Otan.

Sem soluções instantâneas, a Europa tenta alternativas de autonomia militar e monetária de médio e longo prazo, como a criação do E2I e do INSTEX, respectivamente, para uma estrutura de defesa comum e para viabilizar o comércio com o Irã.

A fissura nas relaçóes transatlânticas pode ser conjuntural ou reflexo de transformaçóes sistêmicas da ordem internacional. Em todo caso, nota-se uma crise de autoridade dos Estados Unidos, cujo agravamento ou solução dependerá do que acontecer na segunda metade do governo Trump.

\section{REFERÊNCIAS}

ALLEN, J. NATO members increase defence spending by $\$ 100$ billion after Donald Trump called them "delinquents". The Telegraph, 27 Jan. 2019. Disponível em: <https://bit.ly/2HDSIB9>. Acesso em: 30 jan. 2019.

AMERICA must use sanctions cautiously. The Economist, 17 May 2018. Disponível em: <https://econ.st/2L4bY8F>. Acesso em: 20 out. 2018.

BARNES, J. E.; COOPER, H. Trump discussed pulling U.S. from NATO, aides say amid new concerns over Russia. The New York Times, 14 Jan. 2019. Disponível em: <https://nyti.ms/2TTm67R>. Acesso em: 20 jan. 2019.

COMISSÃO EUROPEIA. Comissão Europeia age para proteger os interesses das empresas da UE que investem no Iráo como parte do compromisso da UE no âmbito do Plano de Açáo Conjunto Global. Bruxelas: Comissão Europeia, 18 maio 2018. Disponível em: <https://bit.ly/2YVvsWE>. Acesso em: 12 dez. 2018.

DOYLE, M. W. Liberalism and world politics. The American Political Science Review, v. 80, n. 4, p. 1151-1169, Dec. 1986.

FUKUYAMA, F. The end of history and the last man. New York: Free Press, 2006. GERMAN exports to Iran growing. Financial Tribune, 6 Jan. 2018. Disponível em: <https://bit.ly/31AWlgv>. Acesso em: 10 jan. 2019.

GOLDBERG, J. The Obama doctrine. The Atlantic, Apr. 2016. Disponível em: <https://bit.ly/1rxfg9B>. Acesso em: 5 jan. 2019. 
HERSZENHORN, D. M. Mike Pompeo rips into Trump's EU critics. Politico, 12 Apr. 2018. Disponível em: <https://politi.co/2M7EBFL>. Acesso em: 20 dez. 2018. IKENBERRY, G. J. Liberal leviathan: the origins, crisis, and transformation of the American world order. New Jersey: Princeton University Press, 2011.

JIM Mattis resignation letter. The Washington Post, 21 Dec. 2018. Disponível em: <https://wapo.st/2GXiaPd>. Acesso em: 4 jan. 2019.

LEWIS, P. Steve Bannon: I want to drive a stake through the Brussels vampire. The Guardian, 21 Nov. 2018. Disponível em: <https://bit.ly/2DC82dV>. Acesso em: 15 dez. 2018.

LUNDESTAD, G. The United States and Western Europe since 1945: from "empire" by invitation to transatlantic drift. New York: Oxford University Press, 2003.

MORAES, R. C. de. A resistível ascensão de Donald Trump: o caminho do sucesso (I). Jornal da Unicamp, 6 dez. 2018. Disponível em: <https://bit. ly/2ZLXxgu>. Acesso em: 10 jan. 2019.

PARAVICINI, G. Angela Merkel: Europe must take "our fate" into own hands. Politico, 28 May 2017. Disponível em: <https://politi.co/2MPJtyE>. Acesso em: 13 jan. 2019.

PENCE says EU must withdraw from Iran deal e stop trying to "break up" sanctions on "vile regime". RT Question More, 14 Feb. 2019. Disponível em: $<$ https://bit.ly/2YPYU0l>. Acesso em: 27 jan. 2019.

SACHS, J. D. Trump's policies will displace the dollar. Project Syndicate, 3 Sept. 2018. Disponível em: <https://bit.ly/2OVINe2>. Acesso em: 10 nov. 2018.

SON of Brazil president Bolsonaro joins Steve Bannon group. France 24, 2 Feb. 2019. Disponível em: <https://bit.ly/2YSjbCj>. Acesso em: 27 fev. 2019. STATEMENT on the Intermediate-Range Nuclear Forces (INF) Treaty. North Atlantic Treaty Organization, 4 Dec. 2018.

STOKES, D. Trump, American hegemony and the future of the liberal international order. International Affairs, v. 94, n. 1, p. 133-150, 2018.

TAYLOR-WYNN, H. Donald Trump misleads on US defense spending, NATO budget. Politifact, 12 July 2018. Disponível em: <https://bit.ly/2FI90qe>. Acesso em: 13 mar. 2019.

TOMLINSON, C. Trump's right hand man in Europe Rick Grenell wants to "empower" European conservatives. Breitbart, 3 June 2018. Disponível em: $<$ https://bit.ly/2YzVa3P>. Acesso em: 11 set. 2018. 
UNITED STATES OF AMERICA. Nuclear posture review. Virginia: Office of the Secretary of Defense, Feb. 2018. Disponível em: <https://bit.ly/2GcDVv9>. Acesso em: 1 mar. 2019.

WALT, S. M. Trump's problem in Europe isn't optics. Foreign Policy, 14 Nov. 2018. Disponível em: <https://bit.ly/2yMQvw8>. Acesso em: 6 jan. 2019. WARD, A. The US held a global summit to isolate Iran: America isolated itself instead. Vox, 15 Feb. 2019. Disponível em: <https://bit.ly/2V3RukC>. Acesso em: 25 jan. 2019.

WOOLF, A. F. Russian compliance with the Intermediate-Range Nuclear Forces (INF) Treaty: background and issues for Congress. Congressional Research Service, 8 Feb. 2019. Disponível em: <https://bit.ly/2kwmXwW>. Acesso em: 20 fev. 2019. 
